This item was submitted to Loughborough's Research Repository by the author.

Items in Figshare are protected by copyright, with all rights reserved, unless otherwise indicated.

\title{
Determinants of relative skeletal maturity in South African children
}

PLEASE CITE THE PUBLISHED VERSION

http://dx.doi.org/10.1016/j.bone.2011.10.029

PUBLISHER

(c) Elsevier

VERSION

AM (Accepted Manuscript)

LICENCE

CC BY-NC-ND 4.0

REPOSITORY RECORD

Hawley, Nicola L., Emily K. Rousham, William O. Johnson, Shane A. Norris, John M. Pettifor, and Noel Cameron. 2019. "Determinants of Relative Skeletal Maturity in South African Children”. figshare. https://hdl.handle.net/2134/15222. 
This item was submitted to Loughborough's Institutional Repository (https://dspace.lboro.ac.uk/) by the author and is made available under the following Creative Commons Licence conditions.

\section{creative
commons}

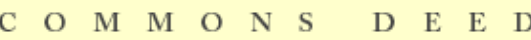

Attribution-NonCommercial-NoDerivs 2.5

You are free:

- to copy, distribute, display, and perform the work

Under the following conditions:

Attribution. You must attribute the work in the manner specified b the author or licensor.

Noncommercial. You may not use this work for commercial purposes.

No Derivative Works. You may not alter, transform, or build upon this work.

- For any reuse or distribution, you must make clear to others the license terms of this work.

- Any of these conditions can be waived if you get permission from the copyright holder.

Your fair use and other rights are in no way affected by the above.

This is a human-readable summary of the Leqal Code (the full license).

\section{Disclaimer 만}

For the full text of this licence, please go to: http://creativecommons.org/licenses/by-nc-nd/2.5/ 


\section{Determinants of Relative Skeletal Maturity in South African Children}

\section{Nicola L Hawley $^{\text {a,e }}$, Emily K Rousham ${ }^{\text {b }}$, William Johnson ${ }^{\text {c }}$, Shane A Norris ${ }^{\text {d }}$, John M Pettifor ${ }^{\mathrm{e}}$}

\& Noël Cameron ${ }^{\text {bee }}$

${ }^{a}$ International Health Institute, Department of Community Health, Brown University, Providence, USA

${ }^{\mathrm{b}}$ Centre for Global Health and Human Development, School of Sports, Exercise and Health Sciences, Loughborough University, Loughborough, UK

${ }^{c}$ Division of Epidemiology and Community Health, School of Public Health, University of Minnesota, Minneapolis, USA

${ }^{d}$ Developmental Pathways for Health Research Unit, Department of Paediatrics, School of Clinical Medicine, University of the Witwatersrand, Johannesburg

${ }^{\mathrm{e}}$ MRC Mineral Metabolism Research Unit, Department of Paediatrics, Faculty of Health Sciences, University of the Witwatersrand, Johannesburg, South Africa

Author Email Addresses:

Nicola L Hawley: $\quad$ Nicola_Hawley@brown.edu

Emily K Rousham $\quad$ E.K.Rousham@lboro.ac.uk

William Johnson wojohnso@umn.edu

Shane A Norris $\quad \underline{\text { san@global.co.za }}$

John M Pettifor J John.Pettifor@wits.ac.za

Noël Cameron $\quad$ N.Cameron@lboro.ac.uk

\section{Correspondence and reprint requests to:}

Nicola Hawley

International Health Institute

Department of Community Health

Brown University

121 South Main Street, Room 258

Providence, RI 02912

USA

Tel:

001-401-419-4300

E-mail:

Nicola_Hawley@brown.edu 


\begin{abstract}
The variation of skeletal maturity about chronological age is a sensitive indicator of population health. Age appropriate or advanced skeletal maturity is a reflection of adequate environmental and social conditions, whereas delayed maturation suggests inadequate conditions for optimal development. There remains a paucity of data, however, to indicate which specific biological and environmental factors are associated with advancement or delay in skeletal maturity. The present study utilises longitudinal data from the South African Birth to Twenty (Bt20) study to indentify predictors of relative skeletal maturity (RSM) in early adolescence.
\end{abstract}

A total of 244 black South African children ( $\mathrm{n}=131$ male) were included in this analysis. Skeletal maturity at age 9/10 years was assessed using the Tanner and Whitehouse III RUS technique. Longitudinal data on growth, socio-economic position and pubertal development were entered into sex-specific multivariable general linear regression models with relative skeletal maturity (skeletal age-chronological age) as the outcome.

At $9 / 10$ years of age males showed an average of 0.66 years delay in skeletal maturation relative to chronological age. Females showed an average of 1.00 year delay relative to chronological age. In males, being taller at 2 years $(\mathrm{p}<0.01)$ and heavier at 2 years $(\mathrm{p}<0.01)$ predicted less delay in RSM at age 9/10 years, independent of current size and body composition. In females, both height at 2 years and conditional weight at 2 years predicted less delay in RSM at $9 / 10$ years $(\mathrm{p}<0.05)$ but this effect was mediated by current body composition. Having greater lean mass at 9/10 years was associated with less delayed RSM in females $(\mathrm{p}<0.01)$ as was pubertal status at the time of skeletal maturity assessment $(\mathrm{p}<0.01)$.

This study identifies several predictors of skeletal maturation at 9/10 years, indicating a role for early life exposures in determining the rate of skeletal maturation during childhood independently of current stature.

\title{
Keywords
}

Skeletal maturity, bone age, South Africa
Abbreviations
Bt20 Birth to Twenty
RSM Relative Skeletal Maturity 


\section{Introduction}

One of the core requirements in evaluating the growth, development, health, and wellbeing of children is the ability to sensitively control for their maturational status. Skeletal maturity or 'bone age' may be used alongside measures of dental and sexual development as a key indicator of biological maturity. The assessment of skeletal maturity is based upon the predictable, ordered appearance of primary and secondary centres of ossification and upon the process of fusion of the epiphyses of long bones. Normal variation in maturation means that chronological age and bone age may differ by \pm two years: for instance a 12 year-old may have a bone age between 10 and 14 years. In a well nourished setting with little constraint on development, being advanced or delayed by more than two years in skeletal maturity relative to reference values is often as a result of underlying endocrine pathology. In a constrained environment the margins of normal variation may be wider. Accordingly, the variation of skeletal maturity about chronological age, within the normal limits, is a sensitive indicator of population health. Age appropriate or advanced skeletal maturity is a reflection of adequate environmental and social conditions, whereas delayed maturation suggests inadequate conditions for optimal development. Comparisons of skeletal maturity between samples of populations can therefore reveal degrees of environmental disadvantage [1-4] while longitudinal observations of maturational markers within a population demonstrate the plasticity of humans in response to environmental change [5]. However, the exposure of healthy children to radiographic assessment has been approached with caution in recent years resulting in few contemporary studies of skeletal maturation and there remains a paucity of data to indicate which biological and environmental factors predict advancement or delay in skeletal maturity and at what stage of development they exert their influence on maturation.

The present study utilises longitudinal data from the South African Birth to Twenty (Bt20) study to investigate which growth and environmental factors are associated with skeletal age deviation in early adolescence.

\section{Material and Methods}

The process of recruitment into the cohort, which occurred in 1990, and the characteristics of the children and their parents from the urban conurbation of Johannesburg-Soweto have been described in detail by Richter et al. [6,7]. Data relating to growth, nutrition, pubertal development, socio-economic status, risk behaviours and cognitive development were collected yearly until age 20. At nine years of age, a sub-sample of the original Bt20 cohort was enrolled into a bone health study to investigate factors affecting the acquisition of peak bone mass. In addition to the standard measurements, whole body duel X-ray absorptiometry (DXA) scans and hand-wrist radiographs were obtained at yearly intervals on the 683 children in this sub-study from age 9 years onwards. 
The present analysis was undertaken using 244 ( $n=131$ male) 9/10 year olds from the Bone Health sub-study. Children were included on the basis of having complete anthropometric and questionnaire data at birth, two, four and 9/10 years; time points selected to represent early and mid-childhood and early adolescence. White children were under-represented in the original Bone Health sample [6] therefore this analysis includes only black children. There were no significant differences $(p<0.05)$ in either growth or socioeconomic characteristics between the children selected for this analysis and the remaining black children in the Bone Health study [8].

\section{Measures}

Hand-wrist radiographs for the assessment of skeletal maturity at age 9/10 years were taken and developed by trained radiographers in the Paediatric X-ray department of the Johannesburg Academic Hospital. The left hand was positioned with the $\mathrm{X}$ ray beam focussed on the distal end of the third metacarpal. The exposure factor used was $42 \mathrm{kV}$ and $12.5 \mathrm{mAs}$ with the distance standardised at $76 \mathrm{~cm}$ in accordance with the optimal radiograph conditions described by Tanner et al. [9]. Skeletal maturity was assessed using the Tanner and Whitehouse III (TW3) RUS technique which includes the radius, ulna, and the metacarpals of the first, third and fifth phalanx [9]. Radiographs were assessed by a single trained observer (NLH). The standard error of measurement calculated to assess intra-observer reliability was 0.107 and within the acceptable limits of error. Skeletal maturity was not assessed at any time point prior to $9 / 10$ years of age.

Standing height was measured at 2, 4 and 9/10 years of age using a Holtain Stadiometer (Holtain Ltd., UK), length at birth was not recorded in this cohort. Weight at 2, 4 and 9/10 years was measured in light clothing with the participant barefoot, using a digital electric scale (Dismed, USA). A fan-beam densitometer (model QDR 4500A; Hologic Inc, Bedford, MA) was used by a trained technician to obtain DXA scans for the assessment of body composition. Fat mass $(\mathrm{kg})$ and lean tissue mass $(\mathrm{kg})$ were calculated with software version 8.21 (Hologic Inc.) using standardised positioning of the subject and consistent procedures for scan analysis. Bone free lean mass was calculated by subtracting total body bone mineral content from total body lean mass. Indices for fat (FMI) and lean mass (LMI) were created to adjust these measures for concurrent stature using the method proposed by Wells and Cole [10]. Both fat and lean mass were divided by height ${ }^{2}$, a power considered appropriate following investigation of the relationships between fat and lean mass and height in this population [10]. To accurately identify those children who are growing more quickly or more slowly within their own environment age- and sex-specific internal $\mathrm{Z}$ scores were calculated for measures of height, weight, BMI, fat and lean mass indices. Pubertal status was assessed by a physician at nine and ten years of age using the Tanner staging technique for pubertal assessment $[11,12]$. For the purpose of this analysis children were classified as being either pre-pubertal or having entered puberty. The onset of 
puberty was defined by entry into Tanner stage 2 of either breast/genitalia development or pubic hair development.

Household socio-economic status (SES) was assessed by questionnaires administered to the mother or the primary caregiver. Principal component analysis was used to construct indices for SES at the time of birth and at the end of childhood (year 9/10). Two explanatory variables were created: consumer durables, which included ownership of various household items (car, TV, fridge, washing machine, and telephone) $($ Eigen value $=1.62-2.50)$, and sanitation which was a measure of running water and toilet facilities $($ Eigen value $=1.53-1.74$ ). Socioeconomic position was dynamic in this population between the two time points observed, therefore indices at each age could be entered into the same regression analysis (SES variables were all correlated at $\mathrm{r}<0.3$ ).

All subjects and their parents provided informed consent for inclusion in the Bt20 study. Ethical approval for the study was obtained from the University of the Witwatersrand Committee for Research on Human Subjects.

\section{Statistical Analysis}

All statistical analyses were undertaken using the Statistical Package for the Social Sciences (SPSS) version 15.0 (SPSS Inc., Chicago, IL, USA). The outcome of interest for this analysis was relative skeletal maturity (RSM) (RUS skeletal age - chronological age). This measure describes the degree to which a child is advanced or delayed in their skeletal maturation relative to their chronological age, and therefore negates the need to control for chronological age in any model.

A number of anthropometric and socio-economic predictors (shown in Table 2) were identified $a$ priori according to published literature and previous associations with skeletal maturity or body composition in the Bone Health cohort. Each explanatory variable was regressed on RSM (table 3). Those variables that were significantly associated with the outcome $(\mathrm{p}<0.05)$ were retained in the multivariable analysis. Birthweight and current height were also included in the analysis, although non-significant when regressed on RSM, as they have been previously identified to be associated with skeletal maturity in this cohort [13].

Sex-specific multivariable general linear regression models were built to examine the influences of height, weight and BMI on RSM at 9/10 years of age. Males and females were modelled separately, but with the same group of predictors, in order to identify commonalities or differences between the sexes. Separate models were built for each dimension of growth in order to ascertain the independent effects of weight and height on RSM, and also the effect of weight adjusted for height (BMI). To avoid the statistical issues associated with collinearity between measures at multiple time points 
within the same individual, conditional weight, height, and BMI variables at 2, 4 and 9/10 years were created to represent each individual's size given their previous size(s) [14]. Conditional measures represent the residuals from sex-specific regressions of weight Z-score (or length/BMI) on weight Zscores (or length/BMI) at all previous ages. The residuals were standardised to allow comparison of the size of the coefficients at different ages. By design, these conditional variables have no correlation with the variables they are conditional on and can therefore be included in the same regression model without causing issues of collinearity. FMI and LMI were added in a second stage to each model to examine whether potential effects of weight, length or BMI were mediated by differences in body composition.

\section{Results}

Mean RSM was -0.66 years $(\mathrm{SD}=0.57)$ in males and -1.00 years $(\mathrm{SD}=0.96)$ in females, indicating that on average skeletal age was delayed by almost 8 months relative to chronological age in males and by a year relative to chronological age in females. The range of variation in relative skeletal maturity in this sample was greater in females than in males (Table 1).

\section{Table 1 Here}

Table 2 gives descriptive statistics associated with the variables identified $a$ priori for analysis, comparing those individuals who were delayed in skeletal maturity by more than one year with those who were delayed by less than one year relative to chronological age (mean RSM for the whole sample was -0.99 years) . Those individuals whose skeletal maturity at 9/10 years was less delayed (RSM >-1.0 years) were consistently heavier and taller, with greater BMI, fat mass and lean mass (females only). In females only, those with less delayed skeletal maturation were more likely to have entered puberty $\left(55.4 \%\right.$ of those with RSM $>-1.0$ years vs. $12.3 \%$ of those with RSM $<-1.0$ years, $\chi^{2}$ $=23.5, \mathrm{p}<0.001)$.

\section{Table 2 Here, Table 3 Here}

Tables 4 and 5 present the results of the sex-specific multivariable linear regression models for weight, height, and BMI. In males, conditional weight at 2 years and height at 2 years were significant independent predictors of RSM at 9/10 years of age $(p<0.01)$ in the weight and height models respectively (Table 4). In both models these associations with RSM were not mediated by the inclusion of body composition variables at $9 / 10$ years. When weight adjusted for height (BMI) was modelled, no significant predictors of RSM at 9/10 years were identified; furthermore the BMI models were not significant. The model that explained the most variance in RSM at age 9/10 years in males incorporated measures of weight throughout childhood and body composition at age $9 / 10$ years. This model explained $19.7 \%$ of the variance in RSM. 


\section{Table 4 Here}

In females, conditional weight at 2 years and height at 2 years were significant independent predictors of RSM at 9/10 years in the weight and height models respectively $(\mathrm{p}<0.05)$ (Table 5). These associations were, however, mediated in the second stage of the models (models 1B and 2B) by the introduction of body composition measures at $9 / 10$ years becoming non-significant after the inclusion of FMI and LMI at age 9/10 years. When body composition at 9/10 years was accounted for, conditional weight at $9 / 10$ years $(\mathrm{p}<0.01)$, height at $9 / 10$ years $(\mathrm{p}<0.05)$ and lean mass index $(\mathrm{p}<0.01)$ were all positively and significantly associated with RSM. Pubertal status in females was consistently a significant predictor of RSM at 9/10 years $(\mathrm{p}<0.01)$. When weight was adjusted for height in the BMI models pubertal status and lean mass at $9 / 10$ years remained significant predictors of RSM ( $p<0.01$ ). The model that explained the most variance in RSM at age 9/10 years in females incorporated height throughout childhood as well as body composition at age 9/10 years, explaining $46.6 \%$ of the variation in RSM.

\section{Table 5 Here}

\section{Discussion}

This analysis used multivariable general linear regression modelling to determine which growth and socio-economic characteristics, measured at birth and during childhood, were associated with RSM of black children aged 9/10 years in a South African cohort. We have previously reported that all children in the Bt20 cohort, both black and white, had delayed skeletal maturation compared with international references [15]. The children in the present analysis showed similar skeletal delay. Average RSM in males was -0.66 years (SD 0.57 years) and in females was -1.00 year (SD 0.96 years) indicating a substantial delay in skeletal maturation relative to chronological age.

In developed country settings African children have been shown consistently to be more advanced in skeletal development than children of European origin as measured by the appearance of ossification centres in the early years of life [16-18]. Comparisons between black children in Africa [19] and black children in the USA [20], however, show US African American children to be more advanced in terms of their skeletal maturity than Africans living in Africa, suggesting that this observation may be as a result of health and nutritional factors rather than ethnicity itself. While there seems to be a genetically determined potential for advanced skeletal maturation in the African population, it can only be exploited under optimal environmental conditions and the post-apartheid conditions 
experienced by this cohort likely explain the delay in skeletal maturation relative to chronological age reported here.

The fact that growth in early life appears to influence the rate of skeletal maturation in this cohort, with greater attained height and weight at 2 predicting more advanced skeletal maturity, adds further support to an established body of literature reporting the influence of growth in infancy (birth to 2 years) on the timing of maturation. Several studies report, in particular, the relationship between rapid weight gain in infancy and age at menarche in females [21-23]. The results of this analysis suggest that an association between early life growth and the timing of maturation (as measured here by indicators of skeletal maturity) is also evident in males. This study replicates previous findings shown in a combined analysis of children from both the Bt20 Bone Health cohort and the Fels Longidudinal Study (USA) [13]. Rapid weight gain in infancy (an increase in weight-for-age of greater than $0.67 \mathrm{Z}$ scores between birth and 2 years [24]) was associated with greater skeletal maturity at age 9 years in both cohorts, despite their differing environments, with skeletal maturity advanced by the same magnitude in both settings; approximately 2.4 months per standard deviation score increase in weight from 0-2 years [13]. The conditional weight measure used here at 2 years, while not necessarily representing 'clinically significant' rapid infant weight gain, does represent the extent to which a child's rate of growth deviates from the rate predicted based on the individuals birthweight [14]. The finding that greater conditional weight at 2 years is positively associated with RSM at 9/10 years indicates that it is the tempo of growth in the first two years, rather than absolute weight at 2 years, which influences the rate of skeletal maturation. In the absence of skeletal maturity indicators at birth or during infancy, however, we are unable to say whether advanced skeletal maturation predated the greater stature at age 2 in this cohort. Pryor [25] suggested that most variations in the sequence and timing of skeletal maturation are genetically determined, and therefore may be set before birth, something that we are unable to consider in this analysis.

The amount of bone-free lean mass present at 9/10 years was a significant predictor of RSM in females. This finding is consistent with a previous study by Powell et al. [26] where bone-free lean mass had the strongest association with RSM in their cross-sectional study of Australian children. It is unlikely that the association between increased lean mass and advanced skeletal maturation is a causal pathway as the endocrine control of both processes is likely to confound this association. Growth hormone and insulin-like growth factor (IGF-1) are known to increase linear bone growth and maturation and to stimulate increases in lean body mass during childhood, particularly during puberty. Sex steroids, estradiol and testosterone are other potential hormone mediators of the relationship between lean mass and skeletal maturation [27-30]. 
The fact that the amount of lean mass present at 9/10 years was only significantly associated with skeletal maturation in females is likely to be related to the pubertal status of the females, another significant predictor of RSM in this cohort. Many of the females included in this analysis had entered puberty at the time of skeletal maturity assessment, and those who had entered puberty were less delayed in their skeletal maturation compared to their pre-pubertal peers (mean pre-pubertal RSM = 1.34 years, mean pubertal RSM $=-0.31$ years, $\mathrm{t}=-6.25, \mathrm{p}<0.01$ ). In contrast, few males were pubertal at the time of skeletal maturity assessment $(20.6 \%)$ and those that were pubertal were in early puberty (Tanner stage 2).

Having previously identified the tempo of skeletal maturation to be responsive to environmental change over time in this setting [15] it was reasonable to predict that measures of socio-economic position, either at birth or at the time of skeletal maturity assessment, might be associated with RSM at the end of childhood. Indeed, several indicators of SES were significantly associated with RSM in univariable general linear regression analyses, resulting in their inclusion in the multivariable models. When included in the multivariable models with measures of stature and body composition, however, none of the socio-economic predictors retained a significant association with the outcome. Many studies have considered the effect of SES on skeletal maturity with inconsistent findings. Those that study relatively homogenous groups find little association [31-33] between SES and skeletal maturity while those that observe the extremes of SES find consistently that experiencing deprivation (nutritional, economic) delays skeletal maturation $[2,3]$. This sample was a relatively homogenous group of black South African children, living within a defined geographical region, so the finding that no socio-economic predictor was independently associated with RSM may be explained by the lack of variation in socio-economic position within the sample. When children grow in a constrained environment, such as the immediately post-apartheid environment experienced by this cohort, small individual constraints may not be detected sufficiently by the type of analysis used here. It is also possible that the SES acts on skeletal maturation through its influence on childhood growth, something unaccounted for in previous studies of SES and skeletal maturation, but addressed in this analysis. The effect of SES may have been mediated by growth during infancy which was shown to be positively associated with RSM. The fact that a large amount of variation in RSM was unexplained by the models presented here indicates there may also be other dimensions of SES, such as nutritional status, which were not captured by the SES indicators available for this cohort, acting on skeletal maturation.

The strength of this study lies in the use of a longitudinal sample, assessed at several time points during childhood, to identify determinants of RSM. The immediate clinical significance of RSM in late childhood / early adolescence has been reported by Jones and Ma [34], who showed RSM to be 
positively associated with measures of bone strength and to be negatively associated with upper limb fracture risk. The wider significance of RSM at this age for later health or adult stature remains to be explored and necessitates the follow up of these individuals to the completion of skeletal development, something that is possible in this longitudinal cohort and will be addressed in future analyses.

\section{References:}

[1] J.M. Tanner, R.H. Whitehouse, N. Cameron, W.A. Marshall, M.J.R. Healy, H. Goldstein, Assessment of Skeletal Maturity and Prediction of Adult Height (TW2 Method), second ed., Academic Press, London, 1983.

[2] A. Shakir, S. Zaini, Skeletal maturation of the hand and wrist of young children in Baghdad, Ann Hum Bio. 1 (1974) 189-199

[3] G. Pathmanathan, P. Raghavan, Bone age based linear growth and weight of underpriviledged North West Indian children compared with their well-off North West Indian peers, J Anat Soc India. 55 (2006) 34-42

[4] B. Bogin, R.B. McVean, The relationship of socioeconomic status and sex to body size, skeletal maturation and cognitive status of Guatemala schoolchildren, Child Dev. 54 (1983) $115-128$

[5] P.B. Eveleth, J.M. Tanner, Worldwide variation in Human Growth, second ed., Cambridge University Press, Cambridge, 1990.

[6] L. Richter, S.A. Norris, T. de Wet, Transition from Birth to Ten to Birth to Twenty: the South African cohort reaches 13 years of age, Paediatr Perinat Epidemiol. 18 (2004) 290-301

[7] L. Richter, S. Norris, J. Pettifor, D. Yach, N. Cameron, Cohort profile: Mandela's children: the 1990 Birth to Twenty study in South Africa, Int J Epidemiol. 36 (2007) 1-8

[8] N.L. Hawley, Skeletal Maturation and its Variation in South African Children, Unpublished PhD thesis, Loughborough University, 2009.

[9] J.M. Tanner, M.J.R Healy, H. Goldstein, N. Cameron, Assessment of Skeletal Maturity and Prediction of Adult Height (TW3 Method), third ed., W B Saunders Ltd., London, 2001

[10] J. C. K. Wells, T. J. Cole, ALSPAC Study Team, Adjustment of fat-free mass and fat mass for height in children aged 8 y, Int J Obes. 26 (2002) 947-952

[11] W.A. Marshall, J.M. Tanner, Variations in the pattern of pubertal changes in girls, Arch Dis Child. 44 (1969) 291-303

[12] W.A. Marshall, J.M. Tanner, Variations in the pattern of pubertal changes in boys, Arch Dis Child. 45 (1970) 13-23

[13] E.W. Demerath, L.L. Jones, N.L. Hawley, S.A. Norris, J.M. Pettifor, D. Duren, R. Sherwood, A.C. Choh, W.C. Chumlea, B. Towne, R.M. Siervogel, N. Cameron, Rapid infant weight gain and the rate of skeletal maturation during childhood, J Pediatr. 155 (2009) 355361

[14] A.D. Stein, M. Wang, R. Martorell, S.A. Norris, L.A. Adair, I. Bas, H.S. Sachdev, S.K. Bhargava, C.H.D. Fall, D.P. Gigante, C.G. Victora, Growth patterns in early childhood and final attained stature: data from five birth cohorts from low- and middle-income countries, Am J Hum Bio. 22 (2010) 353-359

[15] N.L. Hawley. E.K. Rousham, S.A. Norris, J.M. Pettifor, N. Cameron, Secular trends in skeletal maturity in South Africa: 1962-2001, Ann Hum Biol. 36 (2009) 584-594

[16] S.M. Garn, S.T. Sandusky, J.M. Nagy, M.B. McCann, Advanced skeletal development in low income Negro children, J Pediatr. 80 (1972) 965-969

[17] G.M. Owen, K.M. Kram, P.J. Garry, J.E. Lowe, A.H. Lubin, A study of nutritional status of pre-school children in the United States, 1968-1970, Pediatr. 53 (1974) 597-646

[18] W.A. Marshall, M.T. Ashcroft, G. Bryan, Skeletal maturation of the hand and wrist in Jamaican children, Hum Bio. 42 (1970) 419-435 
[19] D.H. Mackay, Skeletal maturation of the hand: a study of development in East African children, T Roy Soc Trop Med H. 46 (1952) 135-150

[20] R.A. Platt, The skeletal maturation of Negro schoolchildren, Philadelphia, 1956

[21] L. Adair, Size at birth predicts age at menarche, Pediatr. 107 (2001) E59

[22] I. dos Santos Silva, B.L. De Stavola, V. Mann, D. Kuh, R. Hardy, M.E. Wadsworth, Prenatal factors, childhood growth trajectories and age at menarche, Int J Epidemiol. 31 (2002) 405-412

[23] D. Sloboda, R. Hart, D. Doherty, C. Pennell, M.Hickey, Age at menarche: influences of prenatal and postnatal growth, J Clin Endocrinol Metab. 92 (2007) 46-50

[24] K. Ong, M. AhmedP. Emmett, M. Preece, D. Dunger, Association between postnatal catch-up growth and obesity in childhood: prospective cohort study, BMJ. 320 (2000) 967971

[25] J.W. Pryor, Ossification as additional evidence in differentiating identical and fraternals in multiple births, Am J Anat. 59 (1936) 409-423

[26] S. Powell, D. Ma, G. Jones, Determinants of skeletal age deviation in a crosssectional study, J Clin Endocrinol Metab. 93 (2008) 521-526

[27] J.W. Gregory, S.A. Greene, J. Thompson, C.M. Scrimgeour, M.J. Rennie, Effects of oral testosterone undecanoate on growth, body composition, strength and energy expenditure of adolescent boys, Clin Endocrinol. 37 (1992) 202-213

[28] S. Arslanian, S. Suprasongsin, Testosterone treatment in adolescents with delayed puberty: changes in body composition, protein, fat and glucose metabolism, J Clin Endocrinol Metab. 82 (1997) 3213-3220

[29] L. Cuttler, G. Van Vliet, F. Conte, S.L. Kaplan, M.M. Grumbach, Somatomedin-C levels in children and adolescents with gonadal dysgenesis: differences from age-matched normal females and the effect of chronic estrogen replacement therapy, J Clin Endocrinol Metab. 60 (1985) 1087-1092

[30] K.Y. Ho, W.S. Evans, R.M. Blizzard, J.D. Veldhuis, G.R. Merriam, E. Samojlik, R. Furlanetto, A.D. Rogol, D.L. Kaiser, M.O. Thorner, Effects of sex and age on the 24-hour profile of growth hormone secretion in man: importance of endogenous estradiol concentrations, J Clin Endocrinol Metab. 61 (1987) 51-58

[31] E. Waldmann, F.M. Baber, C.E. Field, W.Z. Billewicz, A.M. Thomson, Skeletal maturation of Hong Kong Chinese children in the first five years of life, Ann Hum Biol. 4 (1977) 343-352

[32] S. Takai, Smoothed skeletal maturity curve of Japanese children by TannerWhitehouse 2 (TW2) method and its application, Acta Anat Nipponica. 65 (1990) 436-447

[33] D. Freitas, J. Maia, G. Beunen, J. Lefevre, A. Classens, A. Marques, A. Rodrigues, C. Silvas, M. Crespo, M. Thomis, A. Sousa, R. Malina, Skeletal maturity and socio-economic status in Portugese children and youths: the Madeira Growth Study, Ann Hum Biol. 31 (2004) $408-420$

[34] G. Jones, D. Ma, Skeletal age deviation assessed by the Tanner-Whitehouse 2 method is associated with bone mass and fracture risk in children, Bone. 36 (2005) 352-357 
Table 1: Characteristics of study sample

\begin{tabular}{lrr}
\hline & $\begin{array}{r}\text { Male }(\boldsymbol{N}=131) \\
\text { Mean }(\mathbf{S D})\end{array}$ & $\begin{array}{r}\text { Female }(\boldsymbol{N}=\mathbf{1 1 3}) \\
\text { Mean }(\mathbf{S D})\end{array}$ \\
\hline Age (years) & $9.67(0.45)$ & $9.67(0.45)$ \\
Skeletal Age (years) & $9.01(0.63)$ & $8.67(1.15)$ \\
Relative Skeletal Maturity (years) & $-0.66(0.57)$ & $-1.00(0.96)$ \\
Relative Skeletal Maturity (range in & -2.30 to 1.19 & -2.84 to 2.47 \\
years) & & \\
\hline
\end{tabular}

Table 2: Growth and Socioeconomic characteristics of the sample according to relative skeletal maturity (RSM)

\begin{tabular}{|c|c|c|c|c|}
\hline & \multicolumn{2}{|c|}{ Male } & \multicolumn{2}{|c|}{ Female } \\
\hline & RSM >-1.0 & RSM $<-\mathbf{1 . 0}$ & RSM > -1.0 & RSM $<-\mathbf{- 1 . 0}$ \\
\hline & $N=98$ & $N=33$ & $N=56$ & $N=57$ \\
\hline Birthweight (kg) (Mean [SD]) & $3.2(0.5)$ & $3.2(0.5)$ & $3.1(0.5)$ & $3.0(0.4)$ \\
\hline Gestational Age (weeks) (Mean [SD]) & $37.9(1.7)$ & $38.1(1.4)$ & $37.9(1.9)$ & $38.1(1.3)$ \\
\hline Maternal Age at Birth (years) (Mean [SD]) & $25.2(5.5)^{*}$ & $27.7(6.6)^{*}$ & $25.5(5.9)$ & $27.0(6.7)$ \\
\hline \multicolumn{5}{|l|}{ Maternal Marital Status at Birth } \\
\hline Single $^{a}(\%)$ & 69.4 & 78.8 & 83.9 & 82.5 \\
\hline Married / Cohabiting (\%) & 30.6 & 21.2 & 16.1 & 17.5 \\
\hline \multicolumn{5}{|l|}{ Maternal Education at Birth ${ }^{\mathrm{b}}$} \\
\hline$<$ High school $(\%)$ & 59.2 & 51.5 & 50.0 & 59.6 \\
\hline$>$ High school (\%) & 40.8 & 48.5 & 50.0 & 40.4 \\
\hline Height at 2 years $(\mathrm{cm})($ Mean $[S D])$ & $84.0(3.7)^{* *}$ & $81.2(4.4)^{* *}$ & $83.8(3.6) * *$ & $81.5(3.3)^{* *}$ \\
\hline Weight at 2 years (kg) (Mean [SD]) & $11.9(1.8)^{* *}$ & $10.8(1.4)^{* *}$ & $12.0(1.6)^{* *}$ & $11.0(1.3)^{* *}$ \\
\hline BMI at 2 years $\left(\mathrm{kg} / \mathrm{m}^{2}\right)($ Mean $[\mathrm{SD}])$ & $16.8(2.1)$ & $16.5(2.6)$ & $17.1(2.1)$ & $16.6(1.8)$ \\
\hline Height at 4 years $(\mathrm{cm})($ Mean $[S D])$ & $99.7(4.2)^{* *}$ & $97.4(3.7)^{* *}$ & $99.9(3.8)^{* *}$ & $97.4(3.6)^{* *}$ \\
\hline Weight at 4 years (kg) (Mean [SD]) & $15.8(2.0)^{* *}$ & $14.6(1.6)^{* *}$ & $15.8(2.2)^{* *}$ & $14.6(1.3)^{* *}$ \\
\hline BMI at 4 years $\left(\mathrm{kg} / \mathrm{m}^{2}\right)($ Mean $[\mathrm{SD}])$ & $15.9(1.3)$ & $15.4(1.3)$ & $15.8(1.6)$ & $15.4(1.1)$ \\
\hline Height at 9/10 years (cm) (Mean [SD]) & $134.4(6.3)^{*}$ & $131.6(4.9)^{*}$ & $135.6(6.8)^{*}$ & $132.8(4.8)^{*}$ \\
\hline Weight at 9/10 years (kg) (Mean [SD]) & $30.6(6.3)^{*}$ & $27.7(3.7)^{*}$ & $30.9(6.3)$ & $28.9(4.9)$ \\
\hline BMI at 9/10 years $(\mathrm{kg} / \mathrm{m} 2)($ Mean $[\mathrm{SD}])$ & $16.8(2.4)$ & $15.9(1.8)$ & $17.1(2.0)$ & $16.7(1.8)$ \\
\hline Fat mass at $9 / 10$ years $(\mathrm{kg})($ Mean $[\mathrm{SD}])$ & $6.5(4.1)$ & $6.3(2.9)$ & $10.1(5.2)^{* *}$ & $7.1(3.2)^{* *}$ \\
\hline Lean mass at 9/10 years (kg) (Mean [SD]) & $19.4(3.1)^{* *}$ & $17.5(2.1)^{* *}$ & $19.0(3.1)^{* *}$ & $16.6(2.1)^{* *}$ \\
\hline \multicolumn{5}{|l|}{ Pubertal Status at $9 / 10$ years } \\
\hline Pre-pubertal (\%) & 77.6 & 81.8 & $44.6^{* *}$ & $87.7 * *$ \\
\hline Pubertal (\%) & 22.4 & 18.2 & $55.4 * *$ & $12.3 * *$ \\
\hline \multicolumn{5}{|l|}{$\begin{array}{l}\text { Primary Caregivers Marital Status at 9/10 } \\
\text { years }\end{array}$} \\
\hline Single $^{a}(\%)$ & 50.0 & 45.5 & 55.6 & 70.9 \\
\hline Married / Cohabiting (\%) & 50.0 & 54.5 & 44.4 & 29.1 \\
\hline \multicolumn{5}{|l|}{ Primary Caregivers Education at $9 / 10$ years ${ }^{\text {b }}$} \\
\hline$<$ High school $(\%)$ & 67.7 & 62.5 & 37.0 & 43.6 \\
\hline$>$ High school $(\%)$ & 32.3 & 37.5 & 63.0 & 56.4 \\
\hline
\end{tabular}

a Single includes separated, divorced and widowed

Independent $t$ test (continuous variables) or $\mathrm{Chi}^{2}$ test (categorical variables) $* P<0.05, * * P<$ 0.01 
Table 3: Predictors of Relative Skeletal Maturity at age 9/10 years: Significant predictors identified by univariable linear regression

\begin{tabular}{lcc}
\hline & $\begin{array}{c}\text { Male } \\
\text { B (SE) }\end{array}$ & $\begin{array}{c}\text { Female } \\
\text { B (SE) }\end{array}$ \\
\hline Birthweight & $0.06(0.05)$ & $0.15(0.09)^{*}$ \\
Maternal Age at Birth & $-0.09(0.01)^{*}$ & $-0.00(0.01)$ \\
Sanitation at Birth & $-0.17(0.05)^{* *}$ & $-0.11(0.07)$ \\
Durables at Birth & $0.10(0.05)^{*}$ & $-0.06(0.06)$ \\
& & \\
Pubertal Status & $0.04(0.12)$ & $1.03(0.17)^{* *}$ \\
Sanitation at 9/10 years & $-0.09(0.03)^{*}$ & $-0.01(0.13)$ \\
Durables at 9/10 years & $0.15(0.05)^{* *}$ & $0.02(0.06)$ \\
& & \\
Conditional weight at 2 years & $0.21(0.05)^{* *}$ & $0.27(0.09)^{* *}$ \\
Conditional weight at 4 years & $0.09(0.04)^{*}$ & $0.17(0.08)^{*}$ \\
Conditional weight at 9/10 years & $0.04(0.05)$ & $0.17(0.09)^{*}$ \\
& & \\
Height at 2 years & $0.19(0.05)^{* *}$ & $0.09(0.02)^{* *}$ \\
Conditional height at 4 years & $0.09(0.04)^{*}$ & $0.15(0.09)$ \\
Fat mass index at 9/10 years & & \\
Lean mass index at 9/10 years & $0.03(0.05)$ & $0.38(0.08)^{* *}$ \\
\hline
\end{tabular}


Table 4: Predictors of Relative Skeletal Maturity at age 9/10 years in females: multivariable regression models for weight, height and BMI

\begin{tabular}{|c|c|c|c|c|c|c|}
\hline & \multicolumn{2}{|c|}{ Model 1 (Weight) } & \multicolumn{2}{|c|}{ Model 2 (Height) } & \multicolumn{2}{|c|}{ Model 3 (BMI) } \\
\hline & $\mathbf{A}$ & B & $\mathbf{A}$ & B & $\mathbf{A}$ & B \\
\hline & B (SE) & B (SE) & B (SE) & B (SE) & B (SE) & B (SE) \\
\hline Maternal Age at Birth & $-0.01(0.01)$ & $-0.00(0.01)$ & $-0.02(0.01)$ & $-0.01(0.01)$ & $-0.01(0.01)$ & $0.00(0.01)$ \\
\hline Sanitation at Birth & $0.03(0.07)$ & $-0.03(0.07)$ & $0.01(0.07)$ & $-0.04(0.07)$ & $0.04(0.08)$ & $-0.02(0.07)$ \\
\hline Durables at Birth & $-0.10(0.07)$ & $-0.05(0.06)$ & $-0.10(0.07)$ & $-0.06(0.06)$ & $-0.11(0.07)$ & $-0.05(0.06)$ \\
\hline Pubertal Status & $0.78(0.19)^{* *}$ & $0.52(0.19)^{* *}$ & $0.77(0.19)^{* *}$ & $0.43(0.19)^{* *}$ & $0.90(0.19)^{* *}$ & $0.59(0.18) * *$ \\
\hline Sanitation at $9 / 10$ years & $-0.10(0.14)$ & $-0.06(0.13)$ & $-0.07(0.14)$ & $-0.03(0.12)$ & $-0.12(0.14)$ & $-0.08(0.13)$ \\
\hline Durables at 9/10 years & $-0.07(0.06)$ & $-0.04(0.05)$ & $-0.07(0.06)$ & $-0.05(0.05)$ & $-0.07(0.06)$ & $-0.04(0.06)$ \\
\hline Birth Weight & $0.06(0.09)$ & $0.07(0.09)$ & & & & \\
\hline Conditional weight at 2 years & $0.17(0.08)^{*}$ & $0.01(0.09)$ & & & & \\
\hline Conditional weight at 4 years & $0.10(0.09)$ & $-0.02(0.09)$ & & & & \\
\hline Conditional weight at $9 / 10$ years & $0.10(0.08)$ & $0.18(0.08)^{*}$ & & & & \\
\hline Height at 2 years & & & $0.22(0.09)^{*}$ & $0.12(0.09)$ & & \\
\hline Conditional height at 4 years & & & $0.08(0.08)$ & $-0.04(0.08)$ & & \\
\hline Conditional height at $9 / 10$ years & & & $0.09(0.09)$ & $0.23(0.08)^{* *}$ & & \\
\hline BMI at 2 years & & & & & $0.04(0.09)$ & $-0.07(0.09)$ \\
\hline Conditional BMI at 4 years & & & & & $0.10(0.09)$ & $-0.03(0.08)$ \\
\hline Conditional BMI at 9/10 years & & & & & $0.08(0.08)$ & $0.10(0.08)$ \\
\hline Fat mass index at $9 / 10$ years & & $0.09(0.10)$ & & $0.08(0.09)$ & & $0.11(0.10)$ \\
\hline Lean mass index at $9 / 10$ years & & $0.41(0.10)^{* *}$ & & $0.42(0.10)^{* *}$ & & $0.37(0.09) * *$ \\
\hline Adjusted R $\mathbf{R}^{2}$ & $0.332 * *$ & $0.446 * *$ & $0.325 * *$ & $0.466 * *$ & $0.292 * *$ & $0.426 * *$ \\
\hline
\end{tabular}

$* P<0.05, * * P<0.01$

(Weight, height, BMI, Fat and Lean mass indices expressed as internal z-scores) 
Table 4: Predictors of Relative Skeletal Maturity at age 9/10 years in males: multivariable regression models for weight, height and BMI

\begin{tabular}{|c|c|c|c|c|c|c|}
\hline & \multicolumn{2}{|c|}{ Model 1 (Weight) } & \multicolumn{2}{|c|}{ Model 2 (Height) } & \multicolumn{2}{|c|}{ Model 3 (BMI) } \\
\hline & $\mathbf{A}$ & $\mathbf{B}$ & $\mathbf{A}$ & $\mathbf{B}$ & $\mathbf{A}$ & B \\
\hline & B (SE) & B (SE) & B (SE) & B (SE) & B (SE) & B (SE) \\
\hline Maternal Age at Birth & $0.00(0.01)$ & $0.00(0.01)$ & $0.00(0.01)$ & $0.00(0.01)$ & $0.00(0.01)$ & $0.00(0.01)$ \\
\hline Sanitation at Birth & $0.02(0.05)$ & $0.03(0.05)$ & $0.04(0.05)$ & $0.04(0.05)$ & $0.03(0.05)$ & $0.04(0.05)$ \\
\hline Durables at Birth & $-0.01(0.05)$ & $-0.03(0.05)$ & $-0.02(0.05)$ & $-0.03(0.05)$ & $-0.01(0.05)$ & $-0.02(0.05)$ \\
\hline Pubertal Status & $0.01(013)$ & $-0.03(0.13)$ & $0.01(0.13)$ & $-0.02(0.13)$ & $-0.03(0.13)$ & $-0.05(0.13)$ \\
\hline Sanitation at $9 / 10$ years & $0.03(0.04)$ & $0.02(0.04)$ & $0.05(0.04)$ & $0.05(0.04)$ & $0.01(0.05)$ & $0.00(0.05)$ \\
\hline Durables at $9 / 10$ years & $0.05(0.05)$ & $0.04(0.05)$ & $0.05(0.05)$ & $0.04(0.05)$ & $0.06(0.05)$ & $0.05(0.05)$ \\
\hline Birth Weight & $0.07(0.05)$ & $0.10(0.06)$ & & & & \\
\hline Conditional weight at 2 years & $0.19(0.05) * *$ & $0.24(0.06) * *$ & & & & \\
\hline Conditional weight at 4 years & $0.07(0.05)$ & $0.09(0.06)$ & & & & \\
\hline Conditional weight at $9 / 10$ years & $0.01(0.06)$ & $0.15(0.11)$ & & & & \\
\hline Height at 2 years & & & $0.18(0.05)^{* *}$ & $0.18(0.05)^{* *}$ & & \\
\hline Conditional height at 4 years & & & $0.09(0.05)$ & $0.08(0.05)$ & & \\
\hline Conditional height at $9 / 10$ years & & & $0.03(0.06)$ & $0.03(0.06)$ & & \\
\hline BMI at 2 years & & & & & $0.10(0.05)$ & $0.11(0.08)$ \\
\hline Conditional BMI at 4 years & & & & & $0.05(0.06)$ & $0.05(0.08)$ \\
\hline Conditional BMI at $9 / 10$ years & & & & & $0.02(0.06)$ & $0.07(0.17)$ \\
\hline Fat mass index at $9 / 10$ years & & $-0.18(0.10)$ & & $-0.02(0.06)$ & & $-0.04(0.08)$ \\
\hline Lean mass index at $9 / 10$ years & & $-0.01(0.07)$ & & $0.09(0.06)$ & & $0.05(0.10)$ \\
\hline Adjusted $\mathbf{R}^{2}$ & 0.170* & $0.197 *$ & $0.156 *$ & 0.178* & 0.075 & 0.092 \\
\hline
\end{tabular}

$* P<0.05, * * P<0.01$

(Weight, height, BMI, Fat and Lean mass indices expressed as internal z-scores) 